\title{
Sociodemographic and Lifestyle Statistics of Oldest Old People ( $>80$ Years) Living in Ikaria Island: The Ikaria Study
}

\author{
Demosthenes B. Panagiotakos, Christina Chrysohoou, Gerasimos Siasos, \\ Konstantinos Zisimos, John Skoumas, Christos Pitsavos, and Christodoulos Stefanadis \\ First Cardiology Clinic, School of Medicine, University of Athens, Athens, Greece
}

Correspondence should be addressed to Christina Chrysohoou,chrysohoou@usa.net

Received 27 August 2010; Accepted 17 December 2010

Academic Editor: Undurti N. Das

Copyright (C) 2011 Demosthenes B. Panagiotakos et al. This is an open access article distributed under the Creative Commons Attribution License, which permits unrestricted use, distribution, and reproduction in any medium, provided the original work is properly cited.

Background. There are places around the world where people live longer and they are active past the age of 100 years, sharing common behavioral characteristics; these places (i.e., Sardinia in Italy, Okinawa in Japan, Loma Linda in California and Nicoya Peninsula in Costa Rica) have been named the "Blue Zones". Recently it was reported that people in Ikaria Island, Greece, have also one of the highest life expectancies in the world, and joined the "Blue Zones". The aim of this work work was to evaluate various demographic, lifestyle and psychological characteristics of very old ( $>80$ years) people participated in Ikaria Study. Methods. During 2009, 1420 people (aged 30+) men and women from Ikaria Island, Greece, were voluntarily enrolled in the study. For this work, 89 males and 98 females over the age of $80 \mathrm{yrs}$ were studied (13\% of the sample). Socio-demographic, clinical, psychological and lifestyle characteristics were assessed using standard questionnaires and procedures. Results. A large proportion of the Ikaria Study's sample was over the age of 80; moreover, the percent of people over 90 were much higher than the European population average. The majority of the oldest old participants reported daily physical activities, healthy eating habits, avoidance of smoking, frequent socializing, mid-day naps and extremely low rates of depression. Conclusion. Modifiable risk factors, such as physical activity, diet, smoking cessation and mid-day naps, might depict the "secrets" of the long-livers; these findings suggest that the interaction of environmental, behavioral together with clinical characteristics may determine longevity. This concept must be further explored in order to understand how these factors relate and which are the most important in shaping prolonged life.

\section{Introduction}

Demographic analyses throughout the world suggest that the oldest old (i.e., people of age 80 years and older) are the fastest growing portion of the population [1]. Due to these changes, the United Nations' Global Population Pyramid is undertaking a shift, from the classical shape of a pyramid to a cube [2]. The resultant change in the age distribution of the world's population has been, partially attributed to the medical advancements of the recent years, a reduction in maternal and infant mortality, as well as in improved nutrition [3]. Beyond these global considerations it is of interest that there are places around the world where people live longer and, most importantly, they are physically active even after the age of 100 years. Specifically, in the past years anthropologists observed that people living in Sardinia
(Italy), Okinawa (Japan), Loma Linda (California), and Nicoya Peninsula (Costa Rica) have very high life expectancy, with the percent of people over the age of 90 being at amazing rates as compared with the developed world average rate. These places have been defined as the "Blue Zones" and are a part of a large anthropologic and demographic project [4]. It has been observed that people living in these areas share common behavioral and lifestyle characteristics, despite the different race, nationality, and regional characteristics they have. Particularly, the investigators of the Blue Zones reported that "some lifestyle characteristics, like family coherence, avoidance of smoking, plant-based diet, moderate and daily physical activity, social engagement, where people of all ages are socially active and integrated into the community, are common in all people enrolled in the surveys" [4]. Clearly, longevity is a complex attribute, determined by 
factors such as, exposure to disease, variability in sleeping patterns, smoking, physical activity, and dietary habits, in addition to the indirect emotional and cognitive influence on physiological pathways.

Recently it was reported that people in Ikaria Island (in Greece) have also one of the highest life expectancies in the world [4]. The Ikaria Island is located in the centraleastern part of Aegean Sea (Figure 1). The first name of Ikaria was Dolichi, but through Greek mythology it became connected to Ikarus, the first man who succeeded to fly and commemorates his fall [5]. Total population of the Island is about 8,000 people, and the vast majority of them follow a traditional way of living (i.e., traditional dietary habits that included plant foods, daily physical activities, daily naps, mountain living, low stress). Moreover, Ikaria has eight super-hot, radioactive, saline springs, which flow at various points on the Island's shores. The history of the mineral springs is linked with that of the country. Herodotous (484$425 \mathrm{BC}$ ) was the first observer of curative waters. Indeed, he preceded Hippocrates (460-370 BC) and described a good number of health springs [5]. Thus, the aim of this work was to evaluate various sociodemographic, lifestyle and psychological characteristics of oldest old ( $>80$ years) people participated in the Ikaria Study.

\section{Methods}

2.1. Participants of the Study. The "Ikaria epidemiological study" is a cross-sectional survey that took place in the summer of 2009. In brief, the goals of the study were to evaluate various biological, clinical, lifestyle and behavioral characteristics of the adult population of Ikaria Island. A volunteering-based, multistage sampling method was used to enroll 631 men $(65 \pm 13 \mathrm{yrs})$ and 699 women $(64 \pm$ $13 \mathrm{yrs}$ ), from all areas of the island. Individuals residing in assisted-living centers were not included in the survey. The participation rate was $94 \%$. Specifically for this work, 89 men and 98 women over the age of 80 (average $84 \pm 4 \mathrm{yrs}$ ) and one individual per household were studied.

A group of health scientists (physicians and nurses) with experience in field investigation collected all the required information, using a structured, quantitative questionnaire and standard procedures.

2.2. Bioethics. The study was approved by the Medical Ethics Committee of our Institution and was carried out in accordance with the Declaration of Helsinki (1989) of the World Medical Association. All individuals were informed about the aims of the study, agreed to participate, and provided an informed consent.

2.3. Sociodemographic and Lifestyle Measurements. Mean annual income during the past three years was assessed into four categories: low (inability of earnings to cover vital needs), moderate $(6,000-9,600 €$ per year), good $(9,601-$ $18,000 €$ per year), and very good ( $>18,000 €$ per year). The educational level of the participants was recorded in years of school. Moreover, number of cars owned by the participant, square meters of house or apartment, members of family living together with the individual and marital status were also recorded.

Regarding lifestyle characteristics, current smokers were defined as those who smoked at least one cigarette per day, and former smokers were defined as those who had stopped smoking at least during the past year. Occasional smokers (less than 7 cigarettes per week) were recorded and combined with current smokers due to their small sample size. The rest were defined as nonsmokers. Physical activity was evaluated using the shortened version of the self-reported International Physical Activity Questionnaire (IPAQ) [6]. Frequency (times per week), duration (minutes per time), and intensity of physical activity during sports, occupation and/or free-time activities were assessed. Participants who did not report any physical activity were defined as sedentary. In accordance with the standard IPAQ scoring procedures, physically active participants were classified into one of the following groups: upper tertile: "vigorous" physical activity ( $<2500 \mathrm{MET} / \mathrm{min} /$ week $)$, middle tertile: "moderate" physical activity (500-2500 MET/min/week), or lower tertile: "low" physical activity (<500 MET/min/week). Dietary assessment was based on a semiquantitative, food frequency questionnaire (FFQ) that has been validated in a previous study [7]. Specifically, consumption (in times per week or month) of the main 15 food groups and beverages (i.e., meat and its products, poultry, fish and fisheries, milk and other dairy products, fruits, vegetables, greens and salads, legumes, refined and nonrefined cereals, as well as coffee, tea, and soft-drinks) was measured on weekly or monthly consumption basis. Alcohol consumption was recorded in $100 \mathrm{~mL}$ wineglasses ( 1 wineglass $=12 \%$ ethanol concentration). Furthermore, overall assessment of dietary habits was evaluated through a special diet score (MedDietScore, range 0-55), which assesses adherence to the Mediterranean dietary pattern [8]. Higher values on the score indicate greater adherence to this pattern and, consequently, healthier dietary habits.

2.4. Psychological Evaluation. Symptoms of depression during the past month were assessed using the self-report Geriatric Depression Scale (GDS) that has been validated for the Greek population $[9,10]$. The following "yes or no" items were included in the GDS questionnaire: "Are you basically satisfied with your life? Have you dropped many of your activities and interests? Do you feel that your life is empty? Do you often get bored? Are you in good spirits most of the time? Are you afraid that something bad is going to happen to you? Do you feel happy most of the time? Do you often feel helpless? Do you prefer to stay at home, rather than going out and doing new things? Do you feel you have more problems with memory than most? Do you think it is wonderful to be alive now? Do you feel pretty worthless the way you are now? Do you feel full of energy? Do you feel that your situation is hopeless? Do you think that most people are better off than you are?" Responses were coded with 1s (for positive answers) and 0s (for negative answers) yielding a total possible score between 0 and 15. For clinical purposes, GDS scores have been used to indicate no depression (0-4), mild depression (5-10), or severe depression (11-15). 


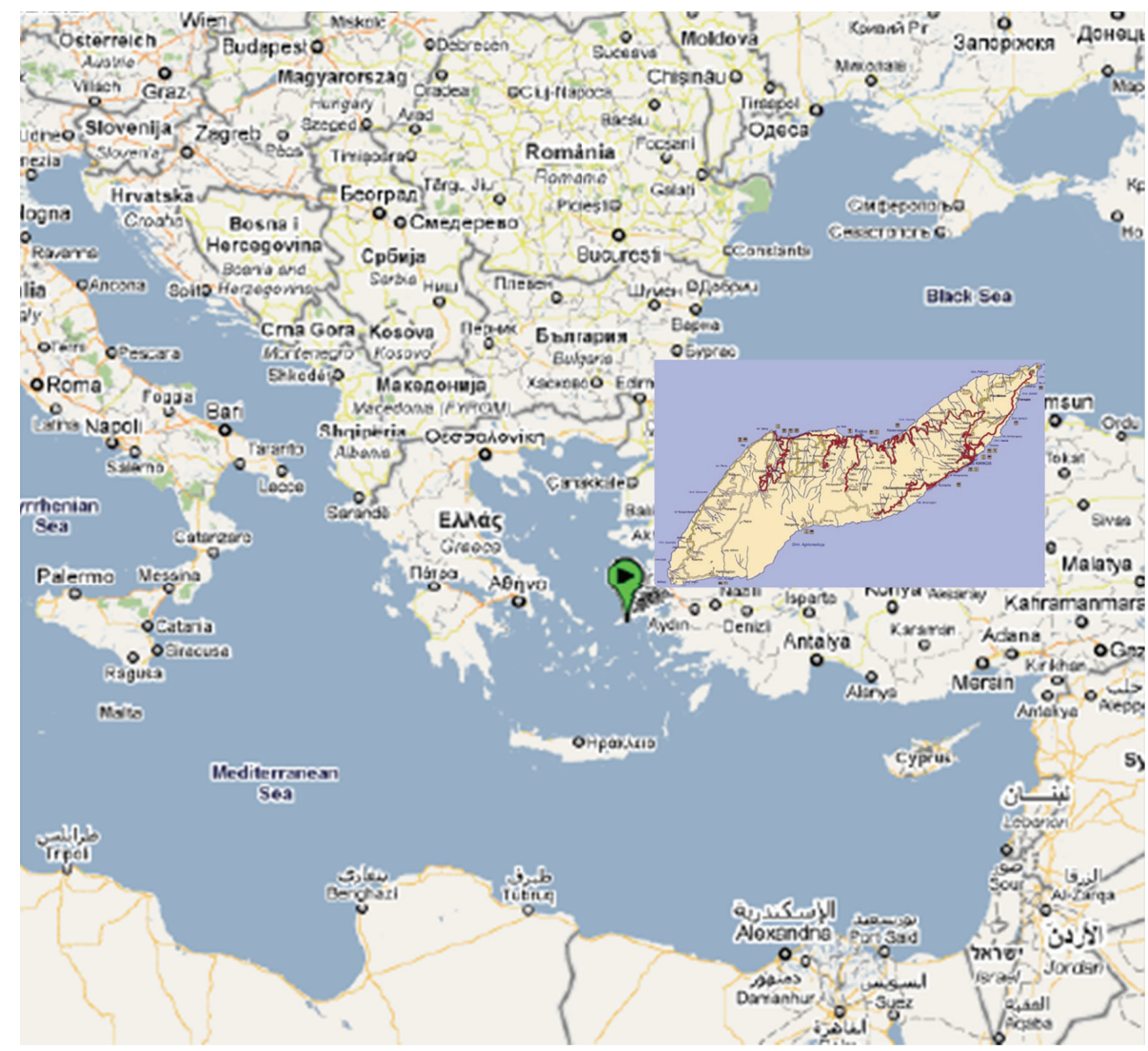

FIgURE 1: The Ikaria Island (Ikaria lies in the east Aegean, within the complex of the East Sporades, between Samos and Mykonos. Area: $255.32 \mathrm{~km}^{2}$, location: $37^{\circ} 35^{\prime} 41.42^{\prime \prime} \mathrm{N}-26^{\circ} 09^{\prime} 30.88^{\prime \prime}$ E, distance from Piraeus $140 \mathrm{~nm}$, coastline length: $160 \mathrm{~km}$, population: 8,312 . Administratively Ikaria is divided into three municipalities, the Municipality of St. Kirykos which is the capital and the south port of the island, the Municipality of Evdilos where is the north port, and the municipality of Rahes which is in the central-west part of the island. Ikaria is exclusively comprised of crystalloid schist metamorphic rocks. Ikaria's wider area has been incorporated in NATURA 2000 network for the protection of natural environments, due to its biophysical variety).

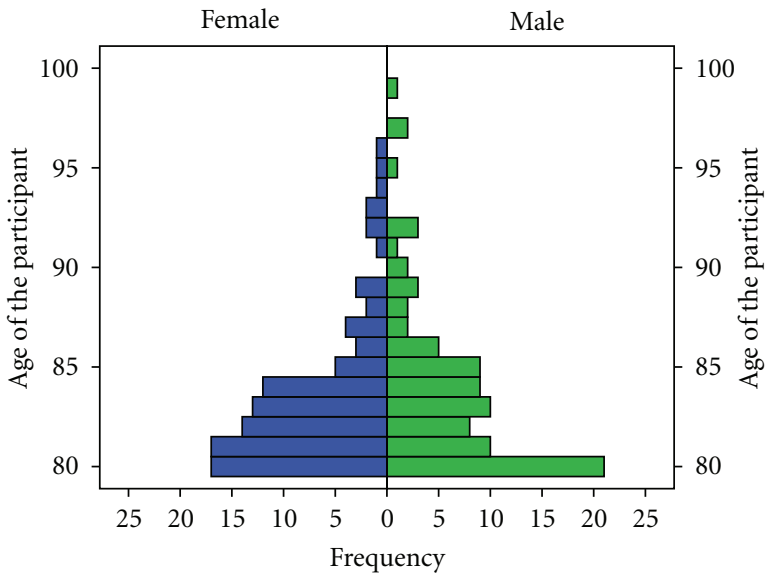

Figure 2: Age pyramid of oldest old (i.e., >80 years) people who participated in the Ikaria Study $(n=187)$.

2.5. Statistical Analysis. Prevalence was defined as the ratio of cases with the specific characteristic by the total sample size. Continuous variables are presented as mean \pm standard deviation (SD) and categorical variables as frequencies. Gender-specific comparisons of continuous variables were performed using the $t$-test (for normally distributed) or the Mann-Whitney $U$-test (for skewed variables). Associations between categorical variables were tested using the Pearson's chi-square test. All tested hypotheses were two-sided. A $P$ value $<.05$ was considered to be statistically significant. SPSS version 18 software was used for all calculations (SPSS Inc., Chicago, Il, USA).

\section{Results and Discussion}

3.1. Sociodemographic Statistics. In Figure 2 the age pyramid of the studied sample is presented. Taking into account that the life expectancy in Greece is 79.78 yrs and the percent of people over 80 years is less than 5\% [11], the Ikaria study's sample consisted of 187 people (13\% of the total study's sample) who were over the life expectancy (i.e., >80 years) of the Greek population. Globally, those 80 years old or over are now only slightly more than $1 \%$ of the total human population; moreover, the oldest old people constitute 3\% of the population of Northern America, almost 3\% of the population of Europe (where only one country, Sweden, has 
more than $5 \%$ in this age group), less than $0.9 \%$ of the population in Asia, Latin America, and the Caribbean, and less than $0.4 \%$ of the population in Africa [12]. In addition, $1.6 \%$ of the men and $1.1 \%$ of women participants in the Ikaria study were over the age of 90 . Finally, the parental age of death of the participants' was 76 years for their father and 80 years for their mother. These figures are of major importance since they suggest that the life expectancy of these people that were born in the late of the 19th century was similar with the current life expectancy of the Greek population (e.g., the life expectancy at the beginning of the 20 th century in Greece was roughly $50-55$ yrs). At this point it could be argued that the applied sampling procedure did not follow strict demographic methodologies, and therefore the age distribution of the study's sample is not representative of the total population of the island. However, the call for participating was for all people aged $30+$ years that they were permanently living in the island, so people from all age groups had equal probability to participate; moreover, taking into account that the proportion of people over 65 years old in Ikaria island is $26 \%$ [11], as well as that older people tend not to participate in surveys like the present, the proportion of oldest old people enrolled in the study could be considered at least close to the actual population rate.

Furthermore, based on demographic data from the United Nations in 2000, the woman to men ratio among people over the age of 80 was roughly 2 to 1 . In our survey this ratio was much lower (i.e., 100 women to 90 men or 1.1 to 1 ); a fact that may lead to the conclusion that men from Ikaria live longer than other men around the world. However, this can also be attributed to limitations in the sampling procedures followed in the study (e.g., volunteering call, women in islands like Ikaria tend not to participate in such surveys).

The gender-specific distribution of various sociodemographic characteristics is presented in Table 1. The majority of men were married, whereas the majority of women were widowed, a fact that could be explained by an old Greek tradition for men to marry much younger women (i.e., usually 5-15 years younger). It is of interest that almost the one half of the oldest old participants of the Ikaria study reported low income (i.e., below their annual average "needs"). It was also reported that a large proportion of people, especially women, were without any pension. Moreover, people were living together with other members of their families (i.e., children, relatives etc.), in relatively small, but own houses.

In addition, $3.3 \%$ of men and $4.1 \%$ of women of these oldest old participants were still working (mainly in their own works), whereas $3.4 \%$ of men and $27.6 \%$ of women were doing works in their houses (i.e., gardening, housekeeping).

The education status of these people was very low, that is, $7.4 \pm 3.4$ years of school, where $20.3 \%$ of them did not complete the primary school, and the illiteracy rate was $10.1 \%$.

3.2. Lifestyle Characteristics. Regarding lifestyle characteristics, the frequency of physical activity varied with gender (Table 2). Men compared with women were more physically active; almost 9 out of 10 men versus 7 out of 10 women reported daily activities (mainly occupational). This proportion of people is much higher than the one reported by the investigators of the MEDIS Study where roughly 1500 elderly (65+ years) people from eight Greek Islands and Cyprus Republic were enrolled $[13,14]$. In particular, in MEDIS Study approximately half of men and one out of four women participants were physically active. Although it is expected that walking and other activities decline with age, nearly 6 out of 10 participants of the Ikaria Study over the age of 90 were still physically active; a proportion which is also very much higher than the one reported by the MEDIS Study investigators (i.e., 20\%) [14]. Very few men and women were current smokers. However, almost all men (i.e., 99\%) and $32 \%$ of women reported ever smoking. These extremely high rates, especially in men, are in discordance with the reported low rates of cancer and cardiovascular disease in Ikaria Island [5].

Dietary characteristics of the MEDIS study sample display a favorable adherence to the Mediterranean diet (with slight differences from the traditional recommendations, especially regarding the increased potatoes consumption) (Table 2). The overall adherence to the Mediterranean diet was good (i.e., average score was $38 / 55$ or $69 \%$ adherence to the traditional dietary pattern), with no differences between genders. Compared with the level of adherence reported by the elderly participants of the MEDIS Study (i.e., 33/55 \pm 4 ), the level observed in the Ikaria Study elders was much higher, suggesting greater dedication to the traditional dietary habits. It seems that westernization and modern food traditions did not affect the lifelong habits of Ikaria people. Moreover, the energy intake was adequate for this specific age-group (Table 2). The observed differences between genders and intake of various foods were of limited nutritional information.

Similar findings as regards dietary habits and prolonged life have already been reported by other studies, too. For example, Knoops and colleagues in the multinational HALE study observed that lower mortality rates from all causes were associated with higher adherence to the Mediterranean diet, moderate alcohol consumption, moderate to high physical activity levels, and nonsmoking [15]. Other studies have also found that regular activity and healthy eating were associated with reduced overall mortality [16-18]. High fruit and vegetable consumption, often exceeding dietary recommendations, was a characteristic of the studied sample. This finding reflects a typical feature of the Mediterranean food culture, since green vegetables eaten not only as a salad dish, but also as the main meal, are usually cooked in olive oil. Moreover, wild plants that are frequently collected and utilized as source of food are widely accepted means of daily living on the Greek islands.

3.3. Psychological Evaluation. Depressive symptomatology as assessed by the GDS was much higher in women as compared with men (Table 3), a fact that confirms many previous reports in other populations. Nevertheless, the average scores were very low (i.e., <5), suggesting absence of depressive symptomatology in this age-group. Comparing these figures 
TABLE 1: Socio- demographic characteristics of the $n=187$ oldest old ( $>80$ yrs) people who participated in the Ikaria Study.

\begin{tabular}{|c|c|c|c|}
\hline & Men & Women & $P$ \\
\hline$N$ & 89 & 98 & \\
\hline$\%$ of people between $85-90$ yrs & 23.6 & 17.3 & .28 \\
\hline$\%$ of people over $>90 \mathrm{yrs}$ & 11.2 & 8.2 & .49 \\
\hline Marital status, $\%$ & & & $<.001$ \\
\hline Never married & 1.1 & 2.0 & \\
\hline Married & 87.7 & 40.9 & \\
\hline Widowed & 9.0 & 46.9 & \\
\hline Divorced & 2.2 & 10.2 & \\
\hline Financial status, $\%$ & & & .39 \\
\hline Low & 41.4 & 49.5 & \\
\hline Moderate & 35.6 & 36.1 & \\
\hline Good & 17.2 & 12.4 & \\
\hline Very good & 5.7 & 2.1 & \\
\hline No. of own cars & $0.8 \pm 0.7$ & $0.3 \pm 0.5$ & .001 \\
\hline Members living within family (children, relatives) & $3.1 \pm 1.6$ & $2.6 \pm 1.9$ & .04 \\
\hline Sq meters of house or apartment & $79 \pm 24$ & $76 \pm 27$ & .53 \\
\hline$\%$ of people with own house or apartment & 97 & 96 & .81 \\
\hline
\end{tabular}

Data are presented as mean \pm SD or relative frequencies. $P$-values derived using the $t$-test or the chi-square test (for the categorical variables).

TABLE 2: Lifestyle and dietary characteristics of the $n=187$ oldest old ( $>80$ yrs) people participated in the Ikaria Study.

\begin{tabular}{|c|c|c|c|}
\hline & Men & Women & $P$ \\
\hline$N$ & 89 & 98 & \\
\hline Physical activity status, \% & & & $<.001$ \\
\hline Low & 16.3 & 29.8 & \\
\hline Moderate & 66.6 & 68.1 & \\
\hline High & 22.1 & 2.1 & \\
\hline Current smoking, \% & 17.0 & 7.0 & .04 \\
\hline Former smoking, $\%$ & 82.0 & 25.0 & $<.001$ \\
\hline MedDietScore (0-55) & $38 \pm 2.7$ & $38 \pm 3.0$ & .97 \\
\hline Energy intake (kcal/day) & $1425 \pm 532$ & $1087 \pm 460$ & $<.001$ \\
\hline Alcohol drinking (mL/day) & $186 \pm 181$ & $117 \pm 114$ & .04 \\
\hline Coffee drinking (mL/day) & $339 \pm 260$ & $293 \pm 228$ & .25 \\
\hline Tea drinking (mL/day) & $109 \pm 84$ & $97 \pm 90$ & .53 \\
\hline \multicolumn{4}{|c|}{ Consumption of food groups in times/week } \\
\hline Olive oil & $6.8 \pm 2.7$ & $5.3 \pm 2.5$ & $<.001$ \\
\hline Cereals & $1.7 \pm 2.5$ & $0.9 \pm 1.7$ & .02 \\
\hline Fruits & $5.5 \pm 3.1$ & $3.9 \pm 2.7$ & .001 \\
\hline Vegetables and salads & $4.8 \pm 2.8$ & $3.5 \pm 2.8$ & .004 \\
\hline Legumes & $2.0 \pm 1.5$ & $1.3 \pm 1.1$ & .001 \\
\hline Fish & $2.1 \pm 1.6$ & $1.5 \pm 1.2$ & .001 \\
\hline Potatoes & $3.3 \pm 0.9$ & $3.1 \pm 0.8$ & .20 \\
\hline Sweets & $1.2 \pm 2.4$ & $1.3 \pm 2.1$ & .88 \\
\hline Red meat and products & $1.8 \pm 1.9$ & $1.2 \pm 1.4$ & .02 \\
\hline
\end{tabular}

Data are presented as mean \pm SD or relative frequencies. $P$-values derived using the $t$-test, the Mann-Whitney test (for food groups), or the chi-square test (for the categorical variables).

with the ones presented by the MEDIS Study that also investigated depressive symptomatology among elders living in Greek islands using the same instrument $[19,20]$, it could be suggested that elders in Ikaria have much lower rates as compared with their peers from the other Greek islands or Cyprus $(25 \%$ of elderly men and $35 \%$ of elderly women participated in the MEDIS study were classified in the highest GDS category, that is, GDS score $>10$, indicating intense depressive symptoms, while $54 \%$ of men and $70 \%$ of women scored above the depression cut-off, that is, GDS 
TABLE 3: Behavioural characteristics (depression and mental health) of the $n=187$ oldest old ( $>80$ yrs) people who participated in the Ikaria Study.

\begin{tabular}{|c|c|c|c|}
\hline & Men & Women & $P$ \\
\hline$N$ & 89 & 98 & \\
\hline Participating in social events, $\%$ & & & .09 \\
\hline Never & 13.3 & 27.7 & \\
\hline Rare & 44.6 & 44.7 & \\
\hline Sometimes during a month & 27.7 & 16.0 & \\
\hline Weekly & 8.4 & 8.5 & \\
\hline Daily & 6.0 & 3.2 & \\
\hline Siesta on daily basis, $\%$ & 84.0 & 67.0 & .006 \\
\hline Geriatric Depression Scale $(0-15)$ & $3.1 \pm 3.3$ & $4.9 \pm 3.5$ & .002 \\
\hline
\end{tabular}

Data are presented as mean \pm SD or relative frequencies. $P$-values derived using the $t$-test or the chi-square test (for the categorical variables).

score $>5$, indicating mild-to-severe depressive symptoms). Moreover, almost all participants of the Ikaria Study reported napping regularly. Slightly more men than women napped; ultimately, all participants over 90 reported sleeping at noon. Recently, in a sample of 23, 681 residents from Greece with no history of chronic disease, the investigators suggested that a midday siesta may reduce a person's risk of death from heart disease, possibly by lowering stress levels [21]. In the present study we had the opportunity to test this hypothesis, too. It was observed that people taking regularly a midday nap had lower GDS scores as compared with those that did not follow this habit $(3.4 \pm 3.0$ versus $5.8 \pm 4.2, P<.001)$. Also, a large present of the studied sample was living together with another person (mostly husband/wife or relative), which may minimize feelings of loneliness. Heather Arthur, studying older adult populations in a secondary prevention setting, reported a consistent relationship between social support, social isolation, and chronic diseases, especially cardiovascular disease [22].

\section{Conclusive Remarks}

The present work investigated "healthy ageing secrets" of long-lived individuals from the Ikaria Island, Greece. It is of major interest nowadays to study characteristics of people living over the expected life span. It is of interest that in 1995, 13\% of the European population was over the age of 65 , while the projection for 2015 is expected to rise to $16 \%$ [2]. Impressively, the present study included roughly $13 \%$ of men and women who were over the age of 80 . Although sampling limitations may exist and do not allow for direct comparisons, the inclusion of the Ikaria Island in the Blue Zones seems to be more rational than ever. Data analysis of the Ikaria Study also revealed that modifiable risk factors, such as physical activity, dietary habits, smoking cessation, and midday naps, might depict the "secrets" of the long livers. The discussed findings are in accordance with previous reports [23] and suggest that the interaction of environmental, behavioral, and clinical characteristics may determine how long an individual lives. This is a widely adopted concept and must be further explored in order to understand how these factors relate and which are most important in shaping longevity.

\section{Conflict of Interests}

No conflict of interests was declared.

\section{Acknowledgments}

The authors are particularly grateful to the men and women from the island of Ikaria, who participated in and collaborated on this survey. The authors also wish to express their gratitude to the Mayors of Rahes, Evdilos, and St. Kyrikos, as well as the physicians of the Health Center of Evdilos (K. Katte, B. Mylonakis, S. Spanou) and the General Hospital of St. Kyrikos (S. Mamatas, G. Skaros). The field investigators of the Ikaria Study are C. Chrysohoou, J. Skoumas, G. Lazaros, G. Siassos, M. Kambaxis, V. Metaxa, D. Tsiachris, K. Dimitriadis, D. Roussos, S. Athanassopoulou, D. Maragiannis, G. Tsitsinakis, M. Zaromytidou, A. Margazas, J. Andreou, A. Patialakas, J. Felekos, D. Aragiannis, P. Kourkouti, E. Giakoumi, S. Lagoudakou, E. Poulidakis, M. Striggou, B. Psaroudaki, C. Masoura, E. Economou, K. Zisimos, E. Christoforatou, A. Valatsou, S. Plytaria, S. Zoulia, S. Kyvelou, E. Gialafos, G. Marinos, G. Vogiatzi, C. Kosifa, S. Vogiatzoglou, and G. Triantafyllou. This work was supported by research grants of the First Cardiology Clinic, School of Medicine, Athens, Greece.

\section{References}

[1] K. Kinsella, "Demographic dimensions of global aging," Journal of Family Issues, vol. 21, no. 5, pp. 541-558, 2000.

[2] J. E. Cohen, "Human population: the next half century," Science, vol. 302, no. 5648, pp. 1172-1175, 2003.

[3] M. Leslie, "Aging: searching for the secrets of the super old," Science, vol. 321, no. 5897, pp. 1764-1765, 2008.

[4] The Blue Zones, 2010, http://www.bluezones.com/about-theblue-zones-community.

[5] Ikaria Island, 2010, http://www.icaria.gr/En/en.html.

[6] C. L. Craig, A. L. Marshall, M. Sjöström et al., "International physical activity questionnaire: 12-country reliability and 
validity," Medicine and Science in Sports and Exercise, vol. 35, no. 8, pp. 1381-1395, 2003.

[7] S. Tyrovolas, G. Pounis, V. Bountziouka, E. Polychronopoulos, and D. B. Panagiotakos, "Repeatability and validation of a short, semi-quantitative food frequency questionnaire designed for older adults living in mediterranean areas: the MEDIS-FFQ," Journal of Nutrition for the Elderly, vol. 29, no. 3, pp. 311-324, 2010.

[8] D. B. Panagiotakos, C. Pitsavos, F. Arvaniti, and C. Stefanadis, "Adherence to the Mediterranean food pattern predicts the prevalence of hypertension, hypercholesterolemia, diabetes and obesity, among healthy adults; the accuracy of the MedDietScore," Preventive Medicine, vol. 44, no. 4, pp. 335340, 2007.

[9] J. A. Yesavage, T. L. Brink, and T. L. Rose, "Development and validation of a geriatric depression screening scale: a preliminary report," Journal of Psychiatric Research, vol. 17, no. 1, pp. 37-49, 1982.

[10] K. N. Fountoulakis, M. Tsolaki, A. Iacovides et al., "The validation of the short form of the geriatric depression scale (GDS) in Greece," Aging —Clinical and Experimental Research, vol. 11, no. 6, pp. 367-372, 1999.

[11] Census data 2001, 2010, www.statistics.gr.

[12] World Population Ageing 1950-2050, Report, DESA, United Nations, 2010.

[13] S. Tyrovolas, A. Zeimbekis, V. Bountziouka et al., "Factors associated with the prevalence of diabetes mellitus among elderly men and women living in Mediterranean Islands: the MEDIS study," Review of Diabetic Studies, vol. 6, no. 1, pp. 2534, 2009.

[14] S. Tyrovolas, V. Bountziouka, N. Papairakleous et al., "Adherence to the Mediterranean diet is associated with lower prevalence of obesity among elderly people living in Mediterranean islands: the MEDIS study," International Journal of Food Sciences and Nutrition, vol. 60, no. 6, pp. 137-150, 2009.

[15] K. T. B. Knoops, L. C. P. G. M. De Groot, D. Kromhout et al., "Mediterranean diet, lifestyle factors, and 10-year mortality in elderly European men and women: the HALE project," Journal of the American Medical Association, vol. 292, no. 12, pp. 14331439, 2004.

[16] A. S. Dontas, J. Moschandreas, and A. Kafatos, "Physical activity and nutrition in older adults," Public Health Nutrition, vol. 2, no. 3 A, pp. 429-436, 1999.

[17] M. Osler and M. Schroll, "Diet and mortality in a cohort of elderly people in a North European Community," International Journal of Epidemiology, vol. 26, no. 1, pp. 155-159, 1997.

[18] C. Lasheras, S. Fernandez, and A. M. Patterson, "Mediterranean diet and age with respect to overall survival in institutionalized, nonsmoking elderly people," American Journal of Clinical Nutrition, vol. 71, no. 4, pp. 987-992, 2000.

[19] E. Mamplekou, V. Bountziouka, T. Psaltopoulou et al., "Urban environment, physical inactivity and unhealthy dietary habits correlate to depression among elderly living in eastern Mediterranean islands: the MEDIS (Mediterranean islands elderly) study," Journal of Nutrition, Health and Aging, vol. 14, pp. 449-455, 2010.

[20] D. B. Panagiotakos, M. Kinlaw, N. Papaerakleous, S. Papoutsou, P. Toutouzas, and E. Polychronopoulos, "Depressive symptomatology and the prevalence of cardiovascular risk factors among older men and women from Cyprus; The MEDIS (Mediterranean Islands Elderly) epidemiological study," Journal of Clinical Nursing, vol. 17, no. 5, pp. 688-695, 2008.
[21] A. Naska, E. Oikonomou, A. Trichopoulou, T. Psaltopoulou, and D. Trichopoulos, "Siesta in healthy adults and coronary mortality in the general population," Archives of Internal Medicine, vol. 167, no. 3, pp. 296-301, 2007.

[22] H. M. Arthur, "Depression, isolation, social support, and cardiovascular disease in older adults," Journal of Cardiovascular Nursing, vol. 21, no. 5, pp. S2-S7, 2006.

[23] E. Tourlouki, E. Polychronopoulos, A. Zeimbekis et al., "The "secrets" of the long livers in Mediterranean islands: the MEDIS study," European Journal of Public Health, vol. 20, no. 6, pp. 659-664, 2010. 


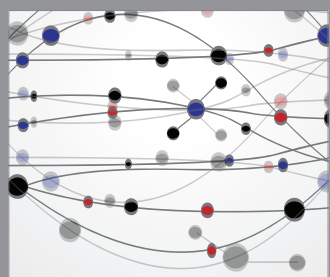

The Scientific World Journal
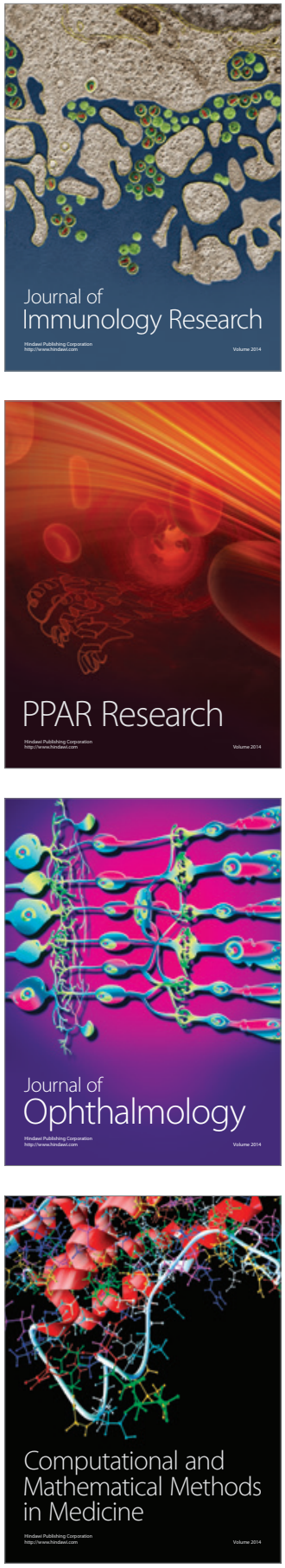

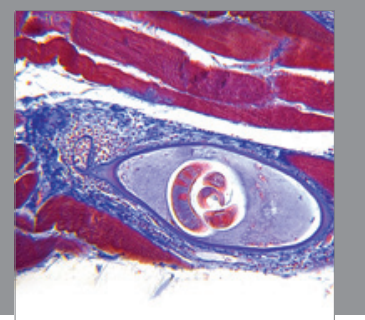

Gastroenterology

Research and Practice
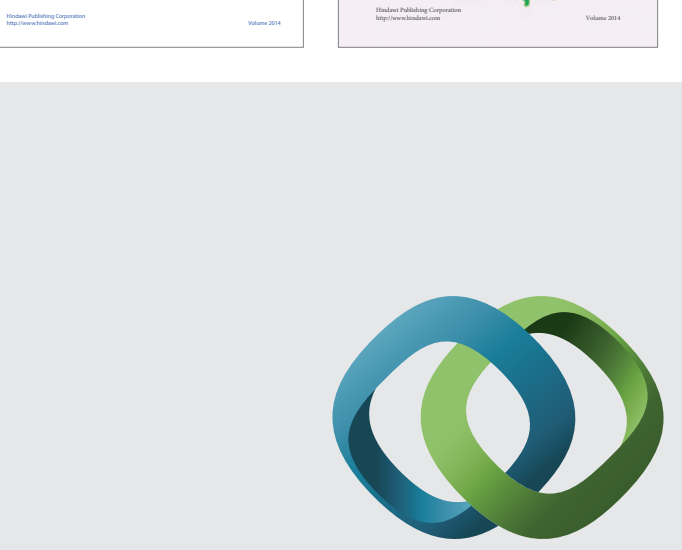

\section{Hindawi}

Submit your manuscripts at

http://www.hindawi.com
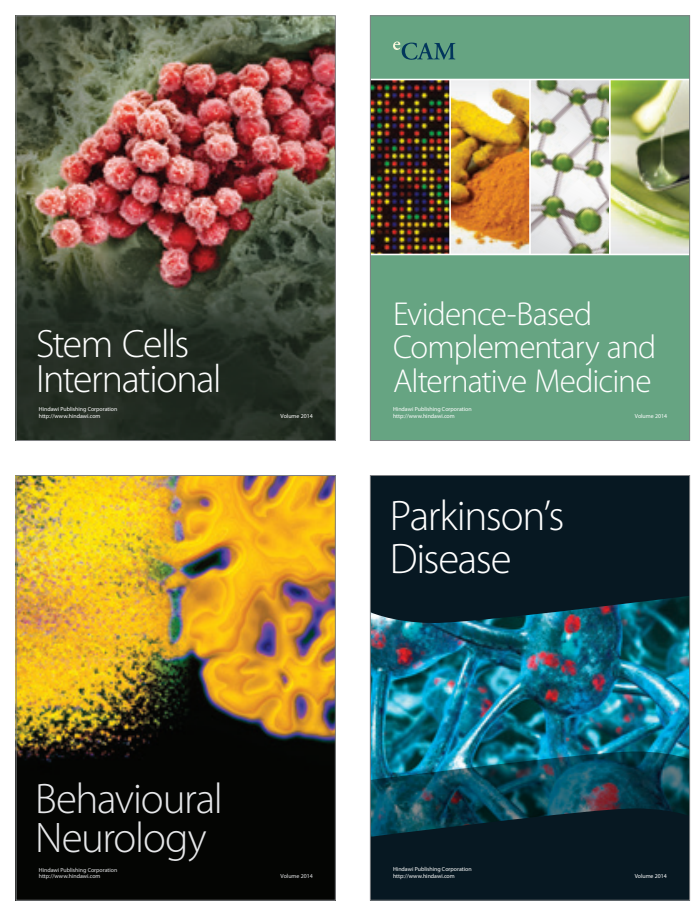

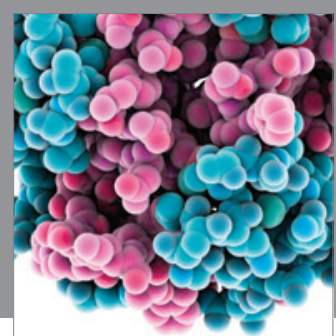

Journal of
Diabetes Research

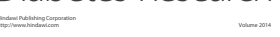

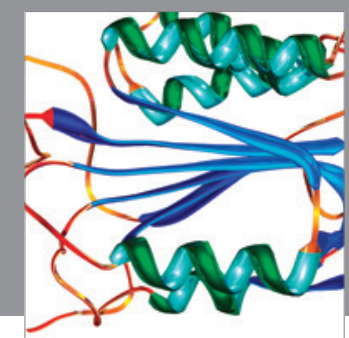

Disease Markers
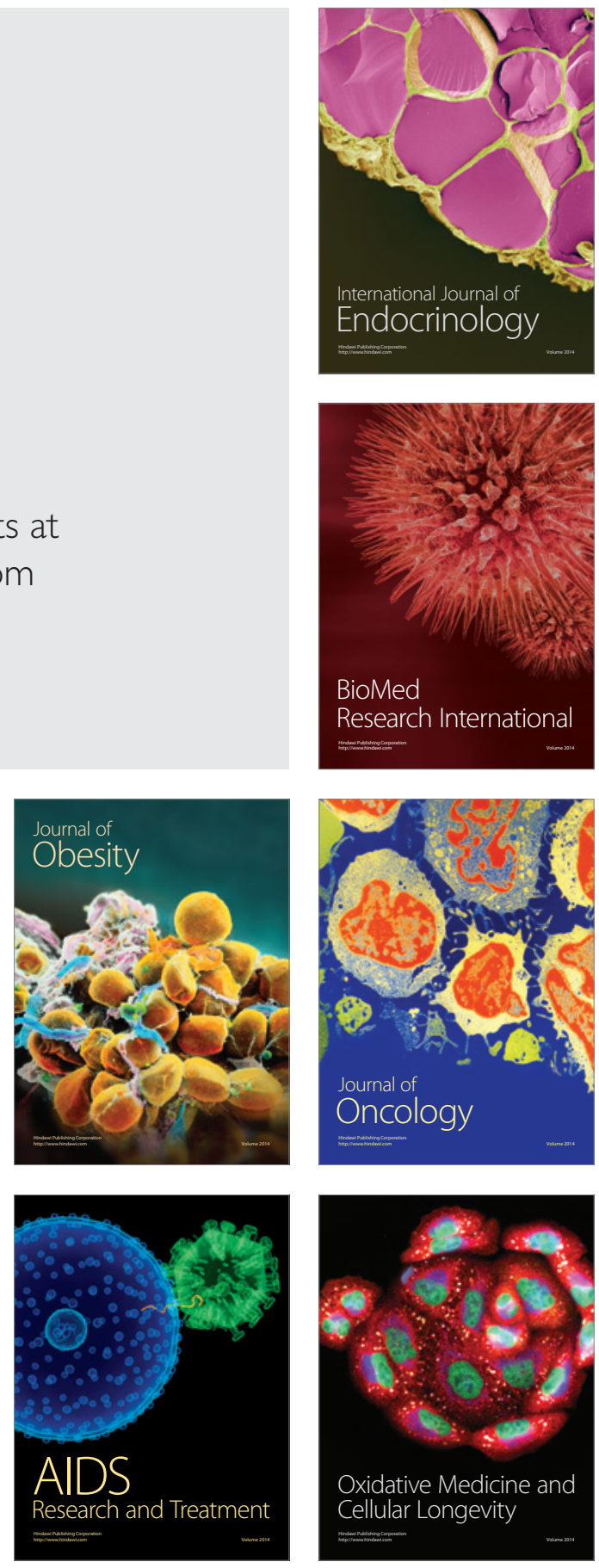